\title{
Hypertension prevalence and its trend in Bangladesh: evidence from a systematic review and meta-analysis
}

\author{
Mohammad Ziaul Islam Chowdhury ${ }^{1 *}$, Meshbahur Rahman², Tanjila Akter², Tania Akhter ${ }^{2}$, Arifa Ahmed², \\ Minhajul Arifin Shovon², Zaki Farhana ${ }^{2}$, Nashit Chowdhury ${ }^{3}$ and Tanvir C. Turin ${ }^{3}$
}

\begin{abstract}
Background: Hypertension, itself being a major chronic condition, is one of the most significant risk factors for premature cardiovascular diseases and mortality. Hypertension is responsible for $13 \%$ of global deaths and threequarters of the world's hypertensive population reside in low- and middle-income countries. Bangladesh is one of those countries that experiencing an epidemiological transition from communicable to non-communicable diseases, a nutritional transition from a traditional diet to process and fast food, and an increase in a sedentary lifestyle, resulting in increased hypertension prevalence. We carried out a systematic review and meta-analysis to identify existing research on hypertension prevalence in Bangladesh, summarize findings and assess its temporal change.
\end{abstract}

Methods: We searched MEDLINE, EMBASE and PubMed and relevant references to identify studies on the prevalence of hypertension in Bangladesh. We used Random-effects meta-analysis to pool the prevalence estimates and performed subgroup analyses. We assessed heterogeneity, a trend in prevalence of hypertension and publication bias in selected studies.

Results: Our search initially identified 735 articles and after removing duplicates, reviewing titles and abstracts, and screening full texts, 53 studies were finally selected. The studies comprised 305,432 subjects and reported overall, gender-specific, geographical location specific and criteria specific prevalence of hypertension. We identified the range of hypertension prevalence is from $1.10 \%$ to $75.0 \%$ and the overall weighted pooled prevalence of hypertension is $20.0 \%$. An extremely high heterogeneity $\left(I^{2}=99.53 \%\right.$; Cochran Q-statistic $\left.p<0.001\right)$ was observed in the prevalence of hypertension. Consequently, we performed subgroup analysis based on gender, age group and geographical location of the study participants, the cut-off level used to define hypertension, and the types of hypertension reported and presented our findings accordingly. An overall increasing trend of hypertension prevalence is also observed.

Conclusions: The prevalence of hypertension is high and rising in Bangladesh. Strategies targeting prevention are required to mitigate a further increase in the prevalence and reduce the morbidity and mortality associated with it.

Keywords: Hypertension, Prevalence, Trend, Bangladesh

\footnotetext{
* Correspondence: mohammad.chowdhury@ucalgary.ca

'Department of Community Health Sciences, University of Calgary, TRW

Building (3rd Floor), 3280 Hospital Drive NW, Calgary, Alberta T2N 4Z6,

Canada

Full list of author information is available at the end of the article
}

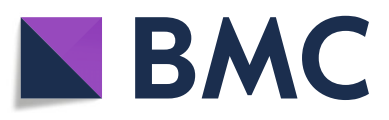

(- The Author(s). 2020 Open Access This article is licensed under a Creative Commons Attribution 4.0 International License, which permits use, sharing, adaptation, distribution and reproduction in any medium or format, as long as you give appropriate credit to the original author(s) and the source, provide a link to the Creative Commons licence, and indicate if changes were made. The images or other third party material in this article are included in the article's Creative Commons licence, unless indicated otherwise in a credit line to the material. If material is not included in the article's Creative Commons licence and your intended use is not permitted by statutory regulation or exceeds the permitted use, you will need to obtain permission directly from the copyright holder. To view a copy of this licence, visit http://creativecommons.org/licenses/by/4.0/. The Creative Commons Public Domain Dedication waiver (http://creativecommons.org/publicdomain/zero/1.0/) applies to the data made available in this article, unless otherwise stated in a credit line to the data. 


\section{Introduction}

Hypertension, itself being a major chronic condition, is one of the most significant risk factors for premature cardiovascular diseases and mortality [1]. Defined as a persistent elevation of blood pressure (BP) beyond 130/80 $\mathrm{mmHg}$ [2], hypertension is directly related to the development of several fatal conditions such as stroke, coronary artery disease, heart failure, atrial fibrillation, and peripheral vascular disease [3]. Persistent untreated hypertension can also lead to kidney failure, dementia and cognitive decline $[4,5]$. Moreover, increased blood pressure can be considered as a marker for other risk factors of noncommunicable diseases (NCD) such as increasing body weight, dyslipidemia, glucose intolerance, and the metabolic syndrome [6]. Hypertension has been attributed to be responsible for $13 \%$ of global deaths [7]. With the projection of a $30 \%$ increase in worldwide prevalence of this condition by the year 2025 and for its pivotal role in the rising global burden of disease and disability, hypertension has become one of the most challenging concerns for world public health [8-10].

Contrary to the popular belief that NCD such as hypertension afflict mostly high-income countries, nearly $80 \%$ of the NCD deaths occur in low- and middle-income countries [11]. Studies estimate that three-quarters of the world's hypertensive population reside in low- and middle-income countries [10] and the prevalence of hypertension is higher in low- and middle-income countries (31.5\%) than in highincome countries (28.5\%) [10]. Bangladesh is one of those low- and middle-income countries that experiencing an epidemiological transition from communicable to non-communicable diseases [12]. On top of that, the ongoing nutritional transition from a traditional diet to process and fast food, increasing trends of sedentary lifestyle due to improved socioeconomic status, congested living conditions and absence of physical movement due to rapid unplanned urbanization may contribute largely to the emergence of hypertension epidemic in Bangladesh. Although Bangladesh successfully combatted against major communicable diseases, this altered pattern of diseases throws a paramount challenge to the health care system of Bangladesh.

Bangladesh currently lacks a population-based surveillance system to track the burden of any noncommunicable chronic disease including hypertension $[13,14]$. In addition, the absence of nationwide population-based surveys or central administrative health data restricts accurate information on the prevalence of diseases like hypertension [13, 14]. Although a handful of studies on the prevalence of hypertension among the Bangladeshi population was conducted, their findings are not consistent. Further, there is also shortage of research that synthesizes existing literature on hypertension prevalence through proper systematic review and meta-analysis. Prevalence estimation in general is based on single large-scale representative survey. Considering absence of accessible nationally representative largescale surveys in Bangladesh, we choose alternative approach to synthesize existing information on hypertension prevalence from the scientific literature through meta-analysis. The purpose of our study is to summarize existing knowledge through systematic review and provide combined/summary prevalence estimates (a combined estimate derived from multiple similar studies that presented same effect measure) using meta-analysis. Meta-analysis, a method to obtain a weighted average of results from various studies offer several advantages. It can provide a more stable estimate than single independent studies because of the increased amount of data uses and hence provides more statistical power to detect effects. Further, it also helps researchers identify inconsistencies/heterogeneity in research findings and explore factors that may explain the sources for these discrepancies. Inadequate information on the magnitude of the condition restrains the health professionals and policymakers from substantiating its extent and undertaking of management plan afterward. To illustrate the actual picture of the current situation, lay bare the discrepancies among hypertension prevalence reported by different individual studies, and make the readers aware of this fact, we carried out this systematic review and meta-analysis using data already published in the literature. Our objective is to assess the prevalence of hypertension in Bangladesh, its trend and to provide comprehensive information that can be used for planning and executing successful preventive strategies for this condition.

\section{Methods}

\section{Data sources and search strategy}

We systematically searched MEDLINE, EMBASE, and PubMed from inception to May 13, 2019, for studies on the prevalence of hypertension among the Bangladeshi adult population. We also searched the reference lists of all relevant publications for information about other potential studies. We limited inclusion to studies published in English. The search strategy focused on three key elements: hypertension, prevalence, and Bangladesh. The search strategy is provided in detail in Table 1. 
Table 1 Search strategy used in different databases

\begin{tabular}{lll}
\hline MEDLINE & PubMed & EMBASE \\
\hline 1. exp Hypertension/ & ((Bangladesh) AND Prevalence) AND & 1. exp hypertension/ \\
2. high blood pressure.mp. & ((((Hypertension) OR High blood pressure) & 2. high blood pressure.mp. \\
3. exp Blood Pressure/ & OR Blood pressure) OR Hyperten*) & 3. exp blood pressure/ \\
4. hyperten*.mp & & 4. hyperten*.mp. \\
5. 1 or 2 or 3 or 4 & 5.1 or 2 or 3 or 4 \\
6. exp Prevalence/ & 6. exp prevalence/ \\
7. exp Bangladesh/ & 7. exp Bangladesh/ \\
8. 5 and 6 and 7 & & 8.5 and 6 and 7 \\
\hline
\end{tabular}

\section{Study selection}

Two reviewers independently using a two-step process identified potentially eligible articles. At first, titles and abstracts were screened. Abstracts were retained if they reported an original study on the prevalence of hypertension in Bangladesh. Review articles were not considered. At this stage, an abstract was retained either when the reviewers agreed that it should be or when there was uncertainty on eligibility based on title and abstract alone. Selected abstracts were subsequently screened based on a full-text review. A broad inclusion criterion was used to provide a comprehensive systematic review of the topic. No restrictions were imposed on study type (e.g., cohort study, cross-sectional study), geographical region (e.g., urban, rural), time period or age groups. There was also no restriction on diagnostic criteria used to define hypertension. A study was included if the prevalence of hypertension was reported in the general adult Bangladeshi population but excluded if the prevalence was reported on individuals with specific diseases (e.g., diabetes). Studies were excluded that did not report the prevalence of hypertension, duplicate, non-human studies, and studies involving children. Agreement between reviewers was quantified. Any disagreement between reviewers was resolved through consensus.

\section{Data extraction and data items}

The following information was extracted from the included studies: author and year of publication; age range of the participants; gender and number of participants; area (urban/rural) in which the study was carried out; sample selection procedure; study design; method for diagnosis of hypertension; cut-off level used to define hypertension and the prevalence of hypertension. Two reviewers independently extracted data using a predefined standardized form.

\section{Summary measures}

The summary statistics from the individual studies were the prevalence of hypertension defined as the number of people in the sample with hypertension, divided by the total number of people in the sample. The prevalence of hypertension could differ considerably depending on the definition of hypertension. As such, we consider all the definitions of hypertension and report the summary results (pooled prevalence) separately based on the definition used to define hypertension. We also presented separate summary results according to the prevalence type, gender, age and geographical location of the study participants assuming potential substantial prevalence differences within these categories.

\section{Statistical analysis}

The pooled prevalence estimates for hypertension and all subgroup analyses and their 95\% confidence intervals were calculated using a random-effects model according to the cut-off level used to define hypertension, types of prevalence reported, gender, age group and geographical location of the study participants. A random-effects meta-analysis model assumes the observed estimates of prevalence (treatment effect) can vary across studies because of both the real differences (heterogeneity) and sampling variability (chance) in the prevalence in each study [15]. Heterogeneity and consistency were assessed using Cochran's Q test and the $\mathrm{I}^{2}$ statistic. Cochran's Q is the classical measure of heterogeneity, which is calculated as the weighted sum of squared differences between individual study prevalence and the pooled prevalence across studies, with the weights being those used in the pooling method $[16,17] . \mathrm{I}^{2}$ measures the percentage of variability in prevalence estimates that is due to between-study heterogeneity rather than chance $[16,17]$. Small study effects were examined using a funnel plot and Egger's test. Inter-rater reliability was measured. All statistical analyses were performed using Stata version 13.1 (Stata Corp, College Station, TX) using the metaprop, metareg, metabias, and metafunnel commands.

\section{Results}

\section{Study selection}

We identified 720 studies on the prevalence of hypertension in Bangladesh through electronic search and a further 15 potentially relevant studies through a grey literature search. After removing duplicates and reviewing titles and abstracts, 89 articles remained for full-text screening. The main reason for exclusion was irrelevance with our study objective. Of the 89 articles full text 
screened, 36 were excluded for the following reasons: 14 were conducted on subjects with diseases, 7 were review articles, 2 studies assessed the association with hypertension, 8 studies conducted on Bangladeshi immigrants living abroad, 1 was carried out on children and 4 were duplicate studies. Consequently, 53 studies were finally selected for this systematic review. There was good agreement (84.21\%) between reviewers on the primary articles eligible for inclusion. The article selection process is shown in Fig. 1.

\section{Study characteristics}

A summary describing the characteristics of the selected studies on the prevalence of hypertension in Bangladesh is presented in Table 2. Twenty-one studies were conducted in rural populations, 8 studies were conducted on urban populations, and 24 studies in both rural and urban populations. Thirteen different cut-off levels or criterion was used to define hypertension and " $\geq 140 / 90 \mathrm{mmHg}$ and/or anti-hypertensive medication" was the most common cut-off value with 22 studies reported this cut-off level. Both genders were represented in almost all studies except 4 studies where study participants were female only. Age of the study participants varied with " $\geq 35$ years" reported by the highest number of studies (13 studies) followed by " $\geq 25$ years" (11 studies) and " $\geq 18$ years" (8 studies) respectively. The study design was cross-sectional in most studies (20 studies) and the cluster-sampling technique was the most commonly used sample selection procedure.

The studies selected in this systematic review comprised 305,432 subjects. Studies reported overall prevalence, gender-specific prevalence, geographical location specific prevalence and criteria specific prevalence of hypertension that ranged from $1.10 \%$ to $75.0 \%$. The weighted pooled prevalence of hypertension regardless of gender, age group and geographical location of the study participants, the cut-off level used to define hypertension, and the types of hypertension reported, was 20.0\% [95\% CI: $18 \%$ - 21\%]. There was an extremely high heterogeneity observed in the prevalence of hypertension $\left(\mathrm{I}^{2}=99.53 \%\right.$; Cochran Qstatistic $\mathrm{p}<0.001)$. One approach to comprehend this problem of high heterogeneity is to identify the factors that may explain the heterogeneity, stratify studies into more homogeneous subgroups accordingly, perform subgroup analysis and finally present corresponding results.

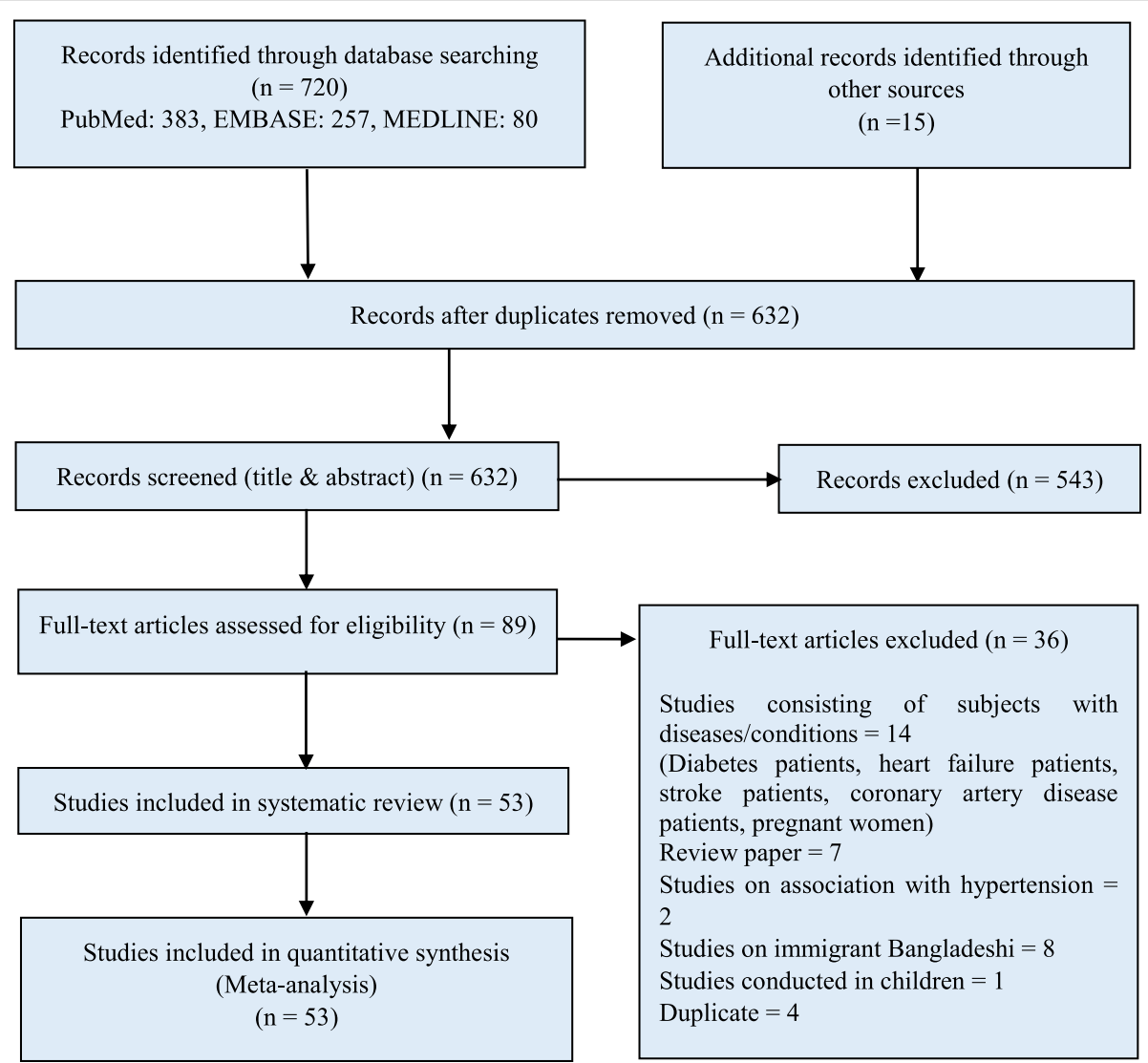

Fig. 1 PRISMA diagram for the systematic review of studies that evaluated the prevalence of hypertension in Bangladesh 


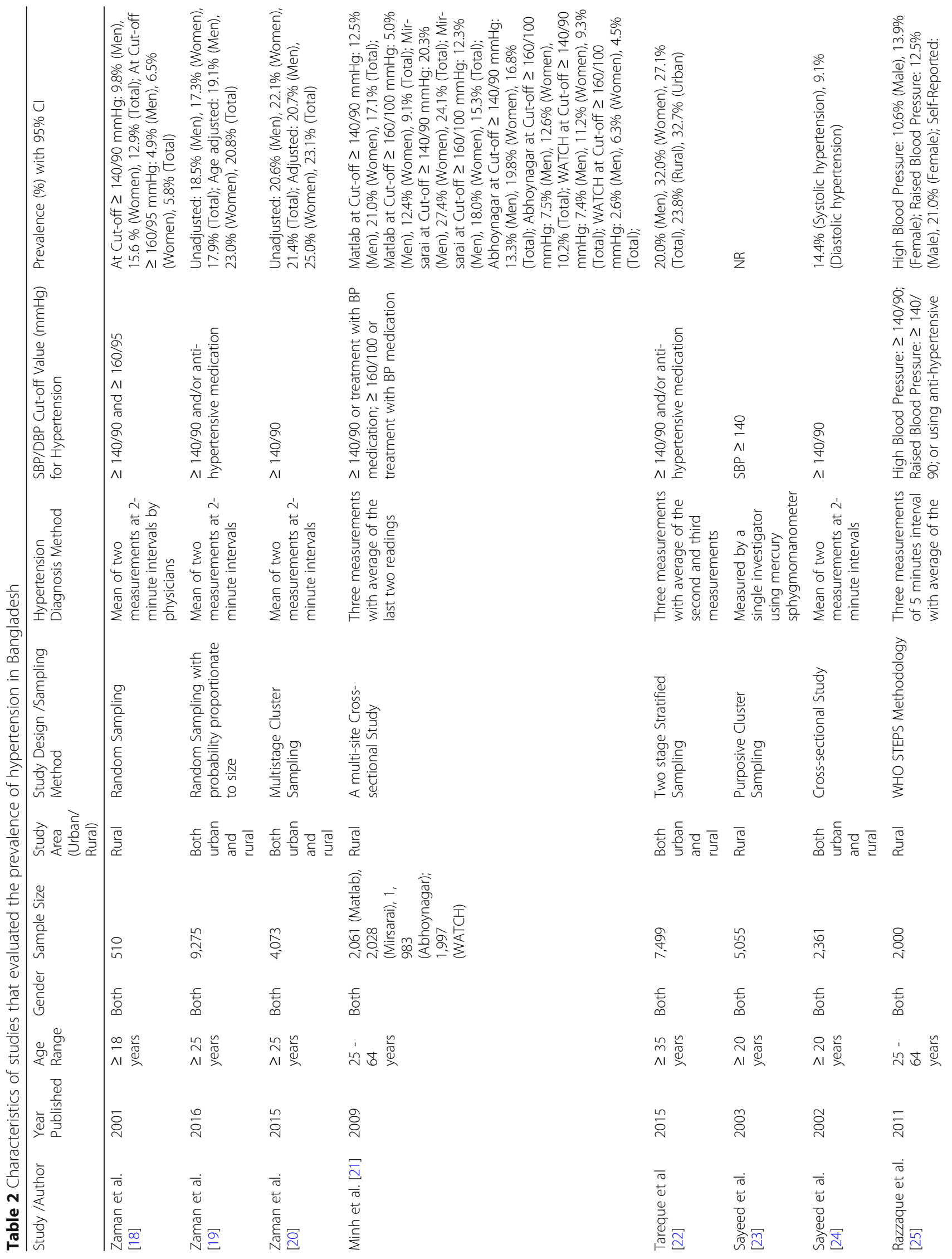




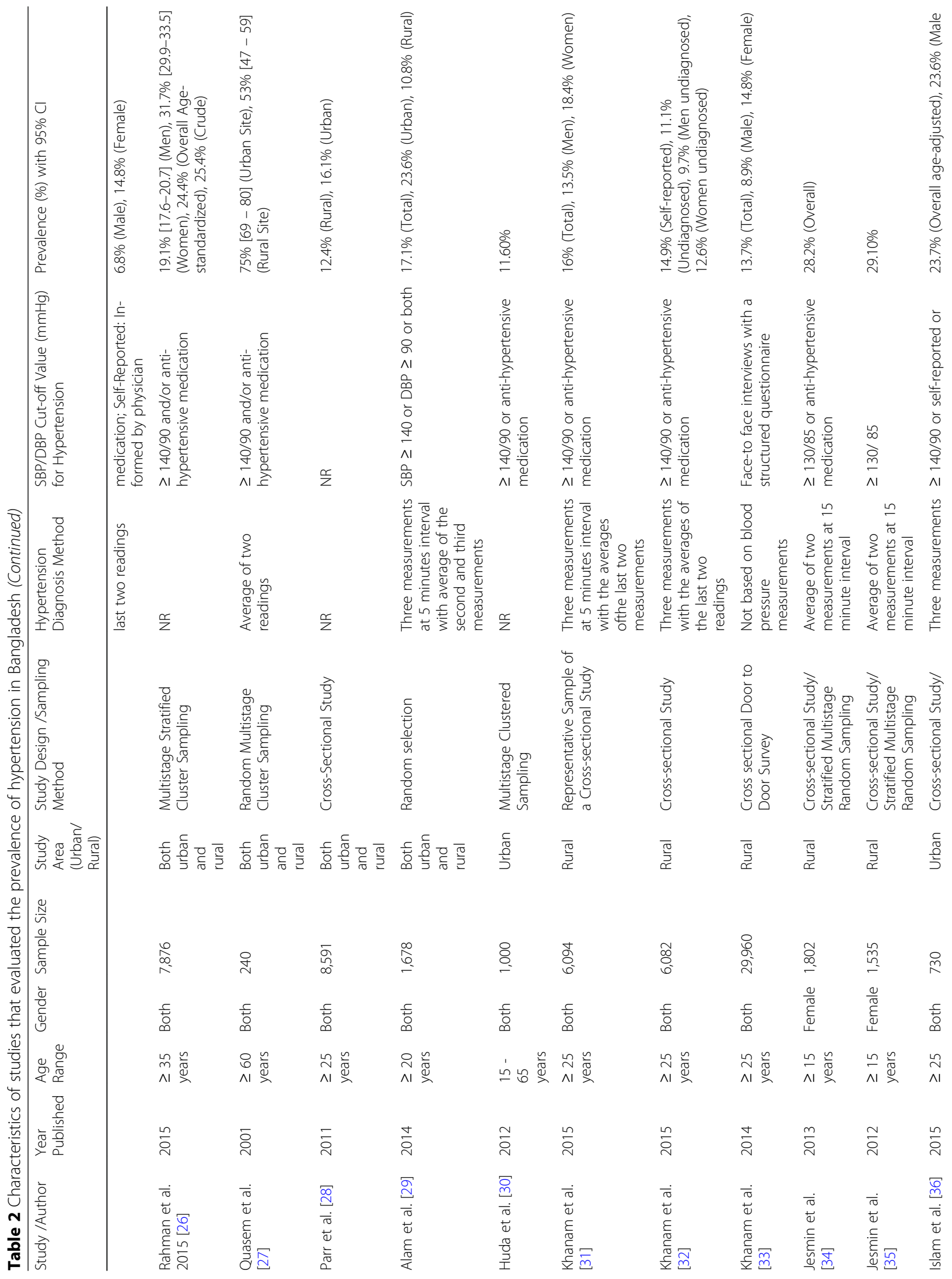


$\begin{array}{ll}\text { Chowdhury et al. Clinical Hypertension } & \text { (2020) 26:10 }\end{array}$

Page 7 of 19

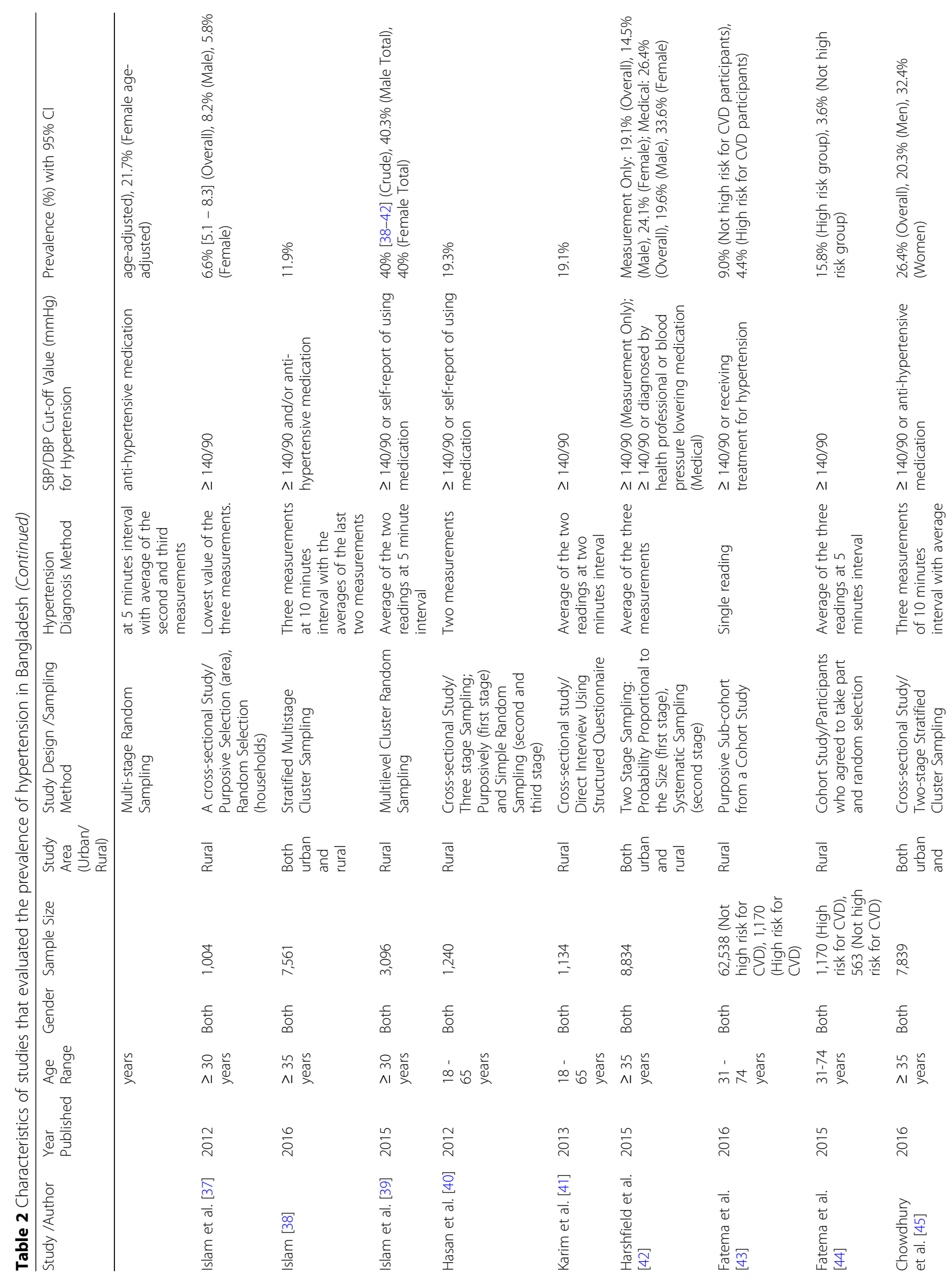




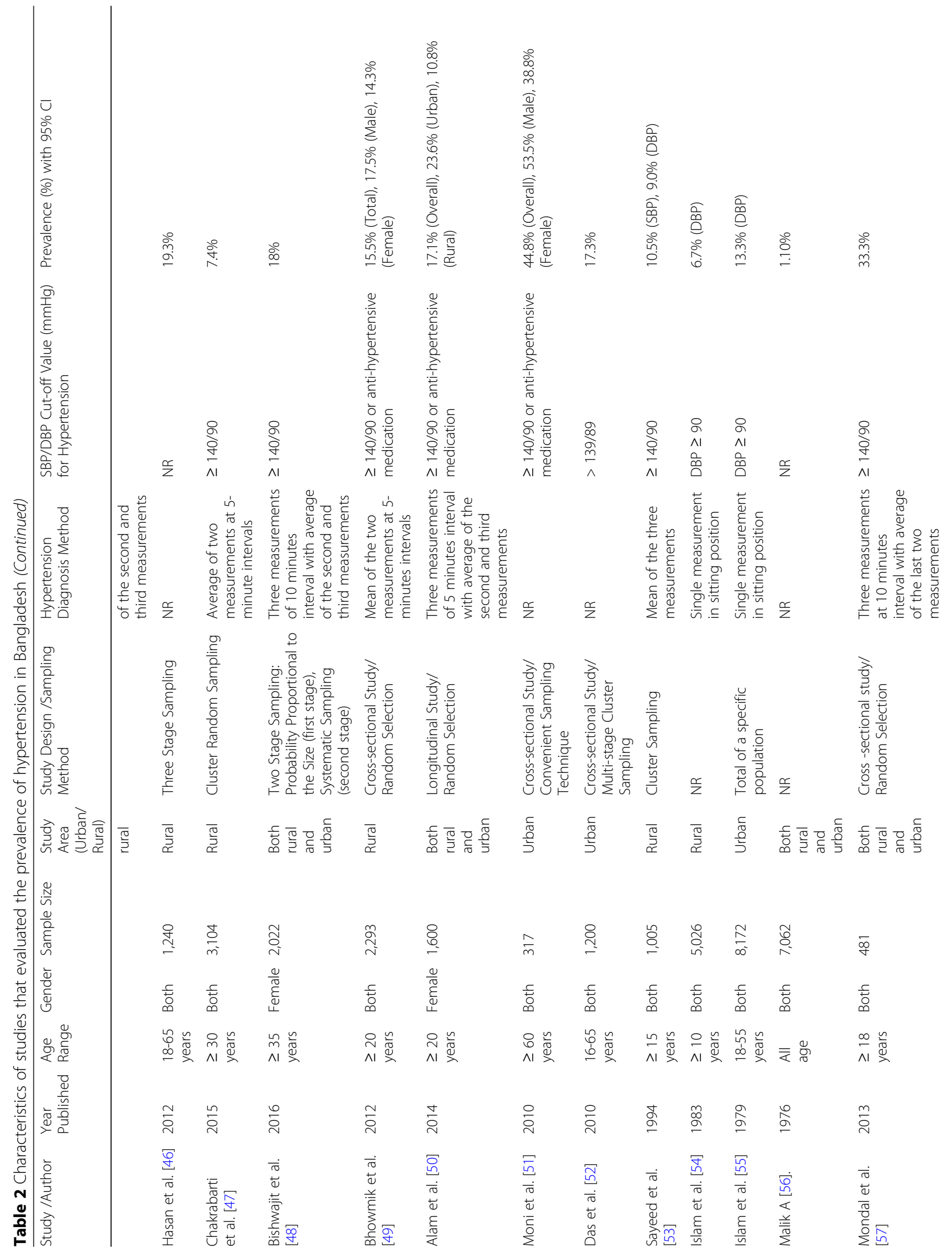




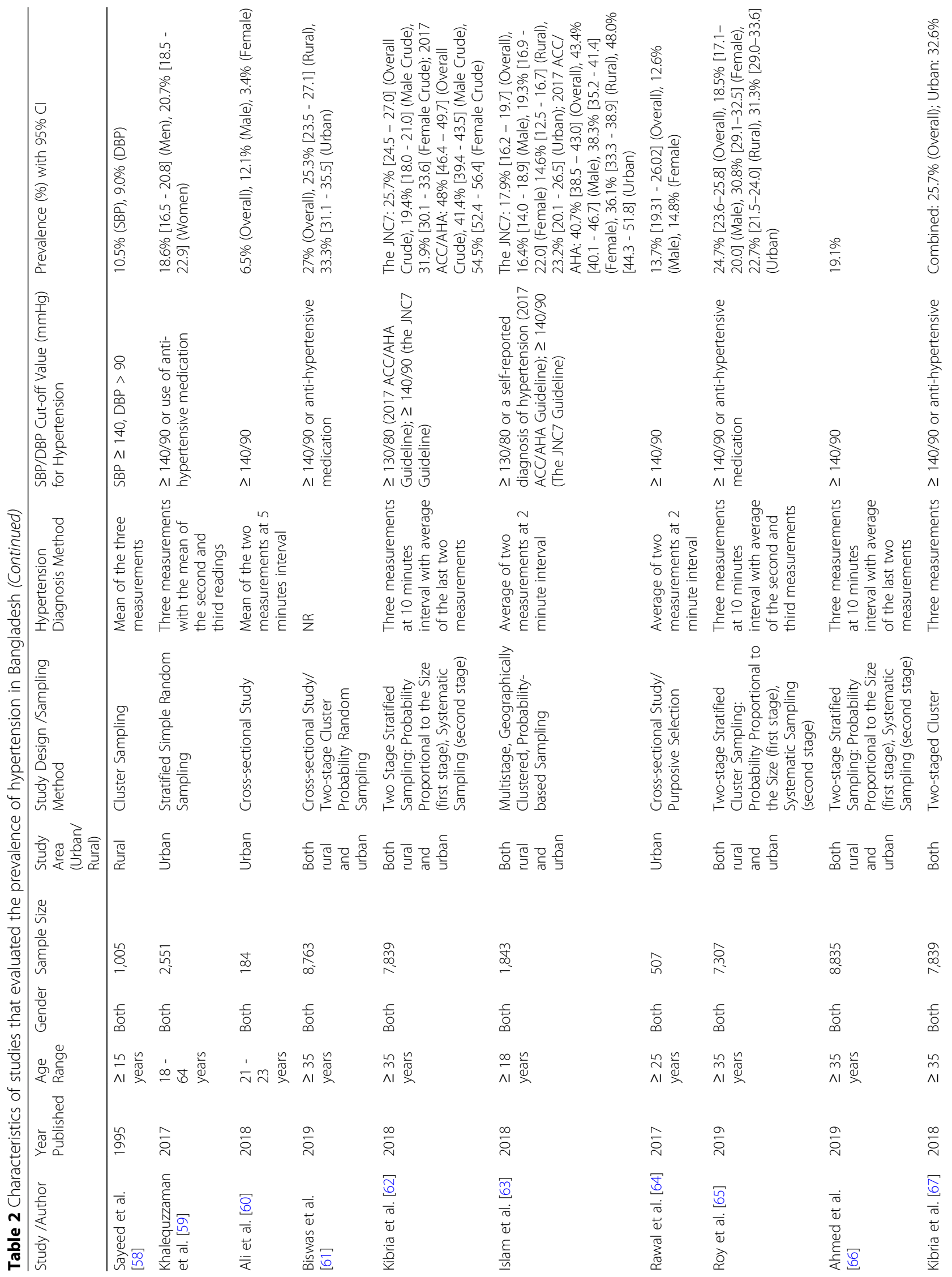


$\begin{array}{ll}\text { Chowdhury et al. Clinical Hypertension } & \text { (2020) 26:10 }\end{array}$

Page 10 of 19

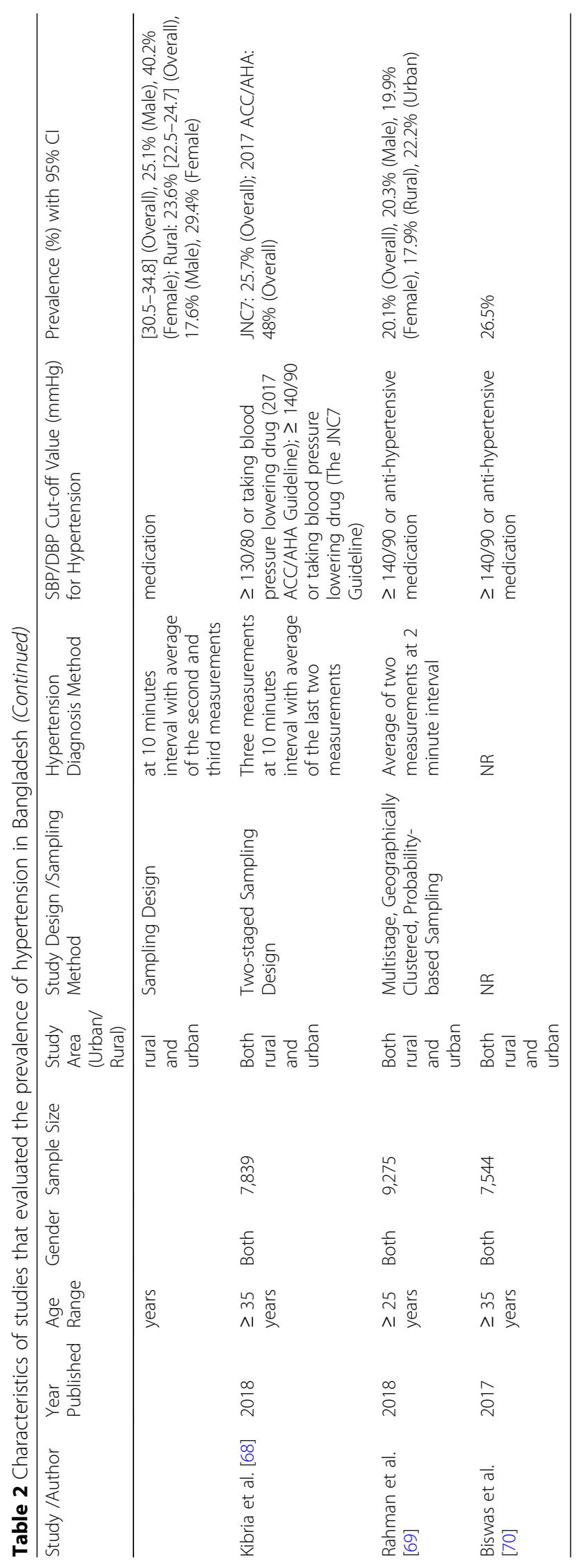


Presenting results in subgroups will help overcome the issue of heterogeneity, results will be more comparable and more informative to the readers to get an in-depth notion about hypertension prevalence in Bangladesh. This will also make readers more aware about potential variability in hypertension prevalence. We performed subgroup analysis based on gender, age group and geographical location of the study participants, the cut-off level used to define hypertension, and the types of hypertension reported and presented our findings accordingly.

\section{Prevalence of hypertension according to the gender of study participants}

The prevalence of hypertension was observed higher in females compared to males. Weighted pooled prevalence of hypertension was 17\% [95\% CI: 14\% - 19\%]) among males, 21\% [95\% CI: 19\% - 24\%]) among females and 20\% [95\% CI: $18 \%$ - 22\%] among combined males and females (Fig. 2).

\section{Prevalence of hypertension according to the age group of study participants}

Generally, hypertension increases with age, which is also evident in this study. Initially, we identified hypertension prevalence reported in 14 different age groups. However, to obtain a pooled prevalence estimate, we merged a few age groups based on their similarities. For example, studies that reported participants age as "15 - 65 years" is merged with " $\geq$
15 years age" group or studies where participants age was reported as " 18 - 65 years" is merged with " $\geq 18$ years age" group. Weighted pooled prevalence of hypertension was lowest 13\% [95\% CI: 5\% $22 \%]$ ) in " $\geq 15$ years age" group, while highest $53 \%$ [95\% CI: $40 \%-66 \%])$ in " $\geq 60$ years" age group (Fig. 3).

\section{Prevalence of hypertension according to the geographical} location of study participants

The prevalence of hypertension and its risk factors could vary substantially in urban and rural areas, particularly in developing countries like Bangladesh due to differences in lifestyles. Weighted pooled prevalence of hypertension was higher in urban areas (25\% [95\% CI: $22 \%$ - 28\%]) compared to rural areas (15\% [95\% CI: 13\% - 16\%]) (Fig. 4). When study participants were from both urban and rural areas, the weighted pooled prevalence of hypertension was reported 24\% [95\% CI: 22\% - 27\%] (Fig. 4).

\section{Prevalence of hypertension according to the cut-off levels used to define hypertension}

The prevalence of hypertension varies according to the cut-off level used to define hypertension in studies. The differences in the cut-off levels for hypertension in the included studies provided a different level of hypertension prevalence (Fig. 5). Although we initially identified 13 different cut-off

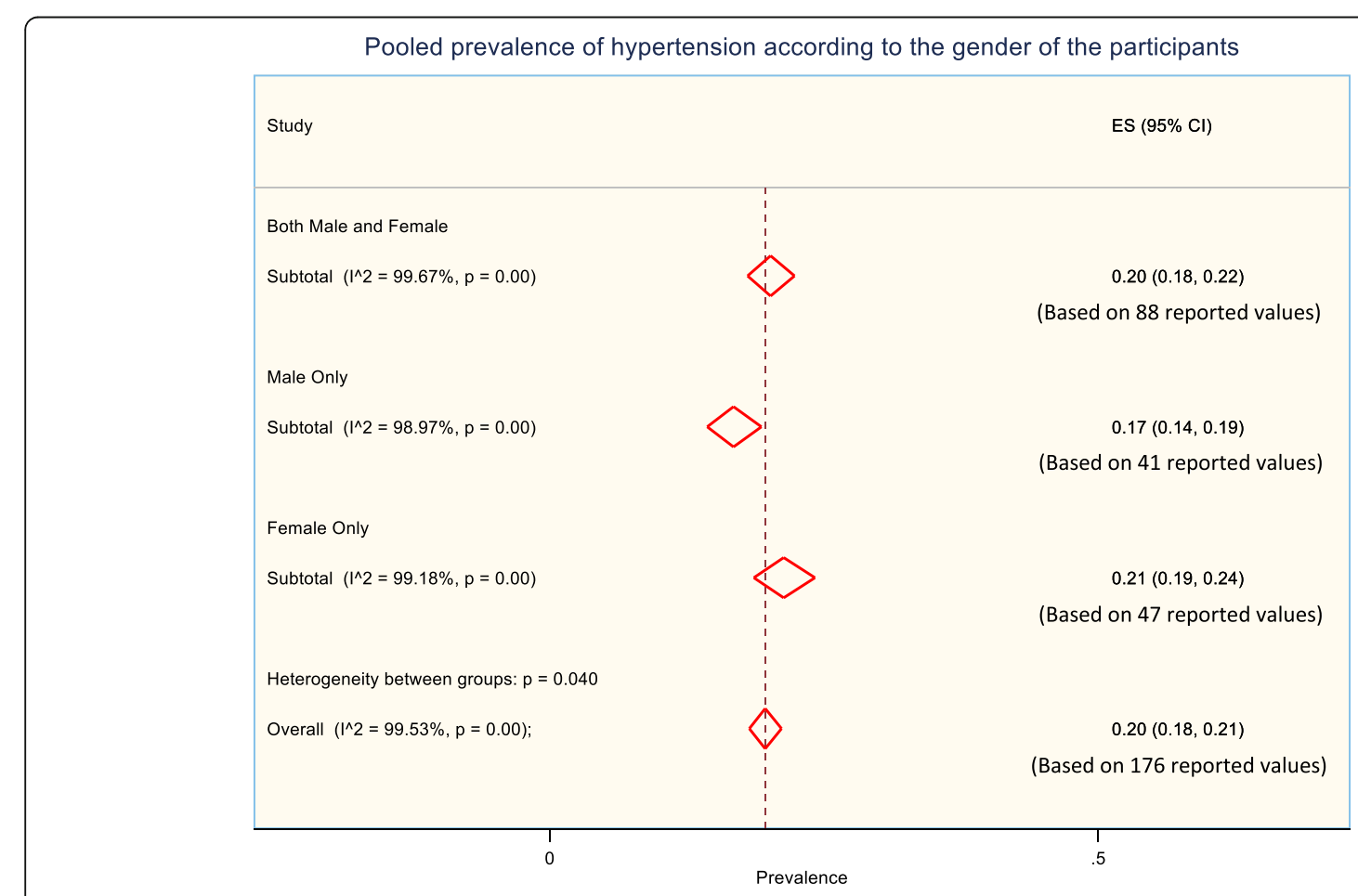

Fig. 2 The pooled prevalence of hypertension according to the gender of the participants 


\section{Pooled prevalence of hypertension according to the participants age group}

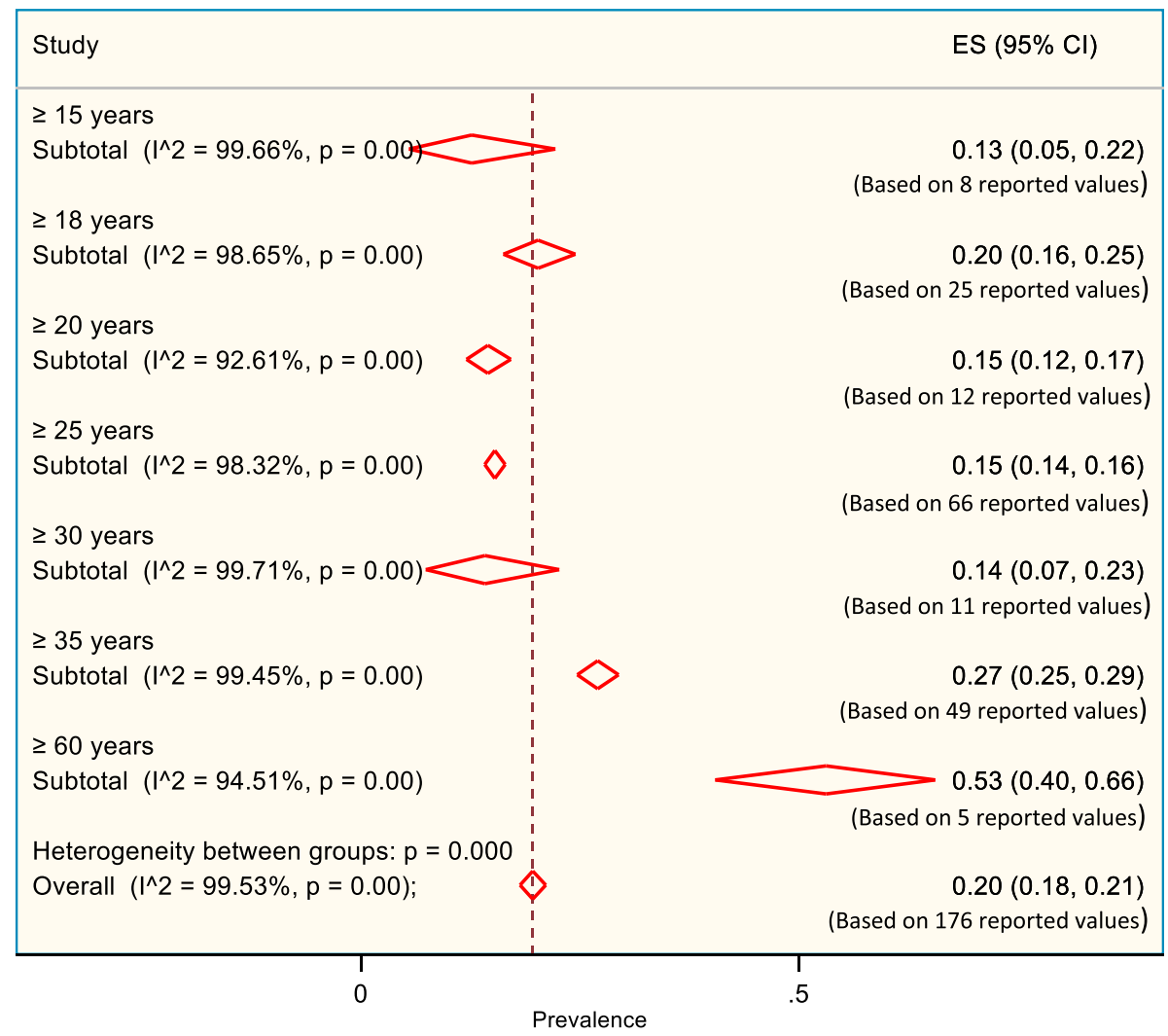

Fig. 3 The pooled prevalence of hypertension according to the participant's age group

values/criteria used by the different studies to define hypertension, we merged them into 7 categories according to the similarities of the cut-off values. For example, cut-off value " $\geq 140 / 90 \mathrm{mmHg}$ or selfreported or anti-hypertensive medication" and " $\geq$ $140 / 90 \mathrm{mmHg}$ or diagnosed by health profession or anti-hypertensive medication" was merged into cutoff value " $\geq 140 / 90 \mathrm{mmHg}$ and/or anti-hypertensive medication" due to their apparent similarity. Highest prevalence was reported $41 \%$ for " $\geq 130 / 80$ $\mathrm{mmHg}$ and/or anti-hypertensive medication" cut-off value while lowest was reported $8 \%$ for " $\geq 160 / 100$ $\mathrm{mmHg}$ and/or anti-hypertensive medication" cut-off value.

\section{Prevalence of hypertension according to the types of prevalence}

Weighted pooled prevalence of hypertension was 19\% [95\% CI: $18 \%$ - 21\%]) when unadjusted, $24 \%$ [95\% CI: $21 \%-27 \%]$ ) when adjusted for age, $23 \%$ [95\% CI: $21 \%$ 25\%] when adjusted to the WHO world population, and $23 \%$ [95\% CI: $18 \%$ - 28\%] when adjusted for age and sex (Fig. 6).

\section{Assessment of temporal change in hypertension prevalence}

The time span among the studies that were conducted ranges from 1976 to 2019. However, the majority of the studies are recent, mostly conducted after 2010. To assess the temporal change in hypertension prevalence, we performed meta-regression on hypertension prevalence over the study year. The overall prevalence of hypertension increased by $0.51 \%$ ( $<<0.001$; Fig. 7) for every 1 -year increase in the study year, suggesting that the prevalence of hypertension is on the rise. However, this increasing trend was not uniform in all groups and categories and there are instances where a decreasing trend was observed. The increase in hypertension prevalence over the time was observed quite similar both in males and in females (Fig. 7a). Over time, an increase in hypertension prevalence was observed in rural areas while a decrease was observed in urban areas (Fig. 7b). An increasing trend in hypertension prevalence was observed when cut-off levels to define hypertension were " $\geq 140 / 90 \mathrm{mmHg}$ ", " $\geq 130 / 80$ $\mathrm{mmHg}$ and/or anti-hypertensive medication", "systolic blood pressure $\geq 140 \mathrm{mmHg}$ ", and "unspecified" 


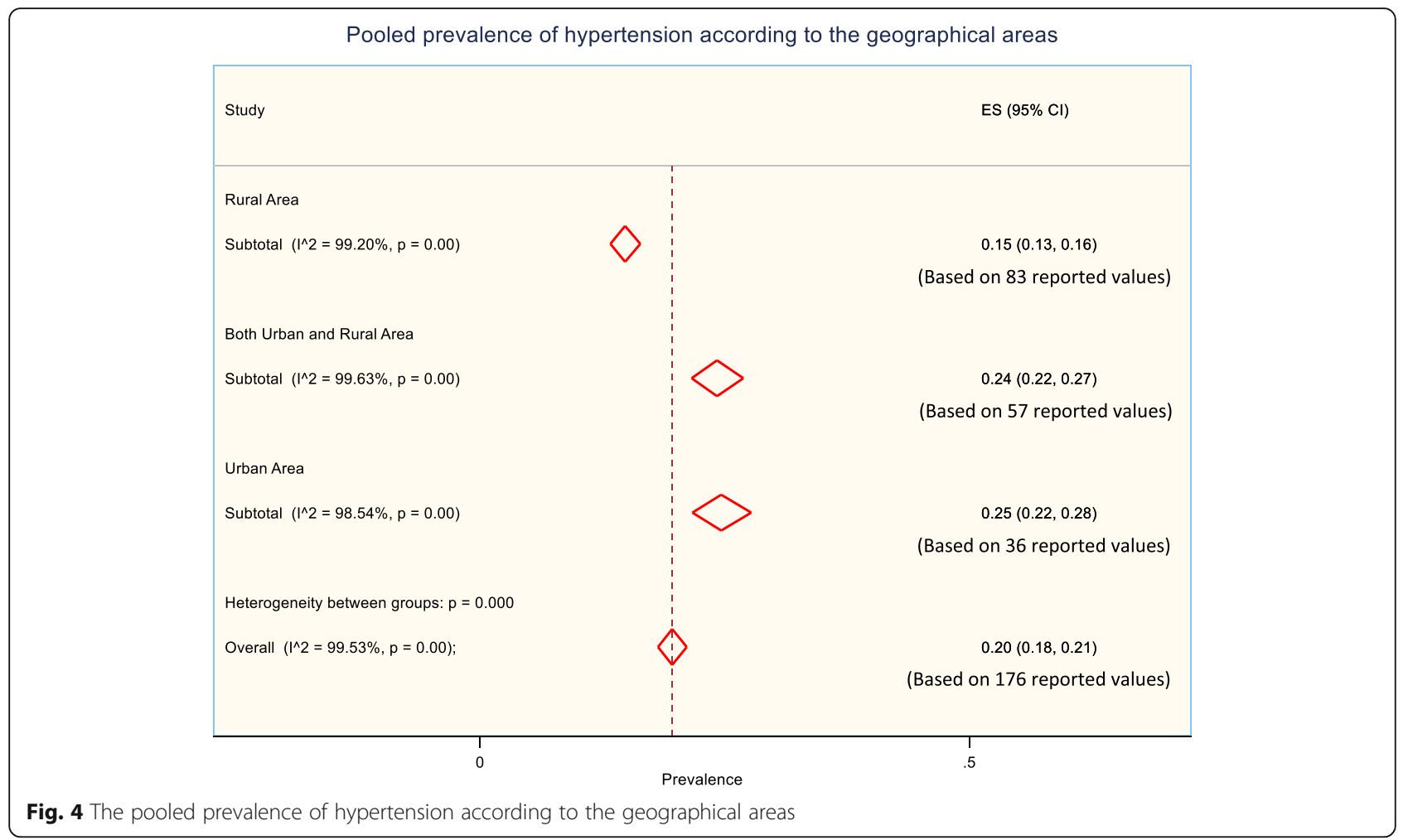

while a decreasing trend was observed in cut-off levels " $\geq 140 / 90 \mathrm{mmHg}$ and/or anti-hypertensive medication" and "diastolic blood pressure $\geq 90$ mmHg" (Fig. 7c). In addition, an increasing trend in hypertension prevalence was observed in all age group categories except " $\geq 20$ years" and " $\geq 60$ years" age group categories where a decline was observed (Fig. 7d).

\section{Publication bias}

The funnel plot indicated the existence of asymmetry and publication bias (Fig. 8) and Egger's test ( $<<0.001$ ) suggested the presence of small-study effects, in which studies of smaller cohorts reported a higher prevalence of hypertension. Funnel plot asymmetry can be due to many reasons other than publication bias. We also do not know with any certainty that publication bias is the true cause of funnel plot asymmetry. As such, we remain cautious in interpreting the results.

\section{Discussion}

In this systematic review and meta-analysis, we describe summary estimates of the prevalence of hypertension and its trend in Bangladesh. Our results present a comprehensive view of the burden of hypertension in Bangladesh. Our findings suggest that the pooled prevalence of hypertension varied widely between $1.10 \%$ and $75.0 \%$ and an overall pooled prevalence of hypertension was estimated to be $20 \%$. Prevalence was observed higher in females, in urban areas, and in the " $\geq 60$ years" age group. Overall, an increasing trend of hypertension was also observed.

Our findings of the overall pooled prevalence of hypertension (20\%) in Bangladesh are quite similar to the global prevalence of hypertension, which is observed 22\% in 2015 among adults aged 18 years and older [71]. The prevalence of hypertension among adults varies across the globe with highest prevalence observed in African region (27\%) while lowest observed in American region (18\%) [72]. A declining trend in hypertension prevalence was observed in high-income countries while stable or increasing trend in prevalence was observed in lowand middle-income countries [71, 72]. According to the World Health Organization (WHO) report published in 2018, prevalence of hypertension (defined as SBP and/or DBP $\geq 140 / 90 \mathrm{mmHg}$ ) among adults (aged $18+$ years) in Bangladesh is $21 \%$ which is not different from what we observed in our findings [72]. While comparing our findings with reports from other neighboring regions, we also see similar results. The WHO reported a prevalence of hypertension among adults in neighboring India, Pakistan, Nepal, and Sri Lanka as $24 \%, 25 \%, 26 \%$, and $24 \%$ respectively in 2015 [72]. Like Bangladesh, an increasing trend in the prevalence of hypertension was also 


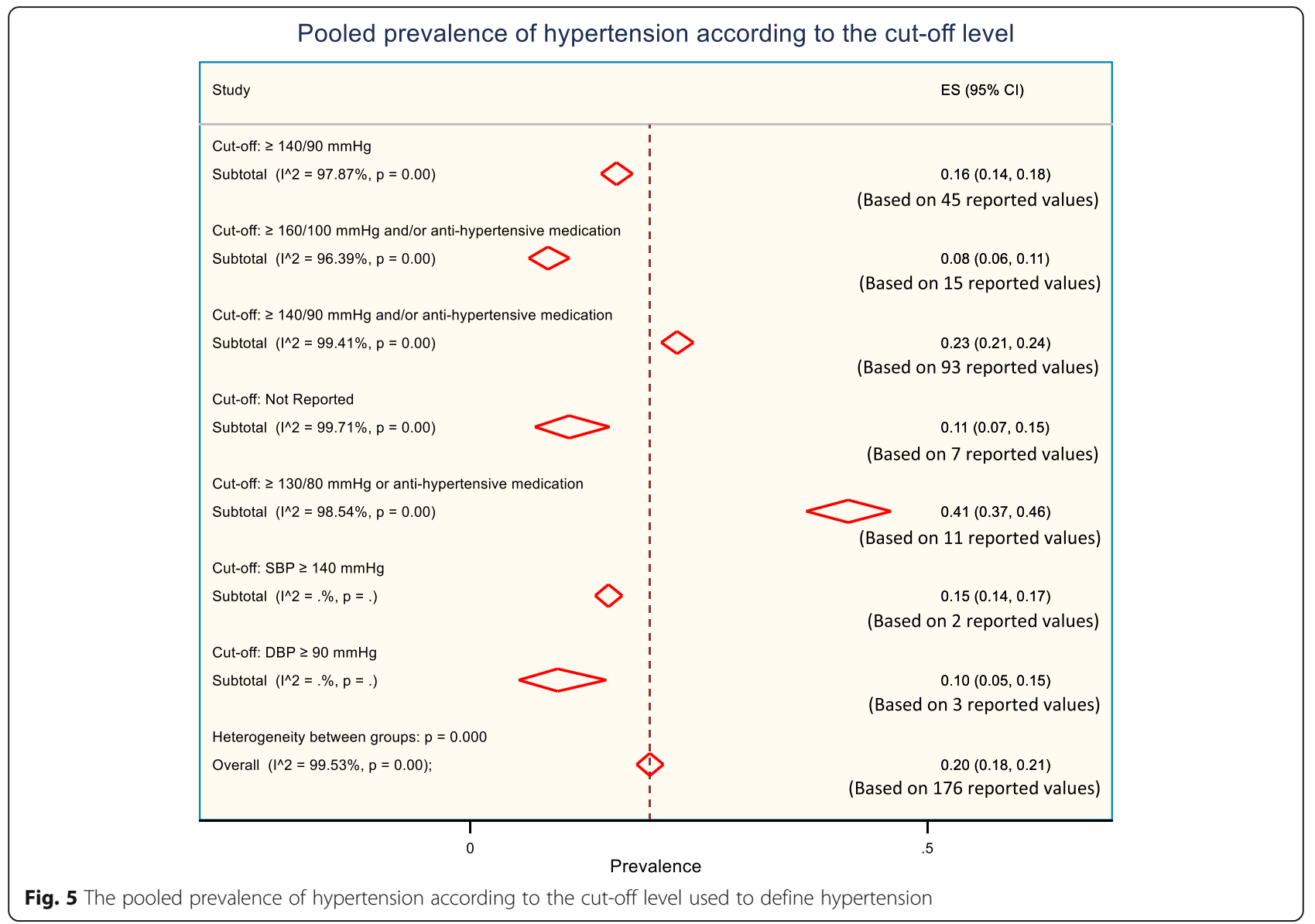

observed in these low- and middle-income countries [72]. Hypertension in general is less prevalent in women, compared with men, particularly among the young. However, it is more prevalent among the elderly women than men [73-75]. In addition, the difference in hypertension prevalence between men and women varies across the global regions. For example, prevalence of hypertension was reported higher among women than men in Arab countries [76]. In neighboring South Asian countries, there is not much difference in hypertension prevalence between men and women [72]. Our contrary findings of higher hypertension prevalence in women could be explained by the higher obesity and less education in women, and potentially older women participation in the study, as all of them are important risk factors for hypertension prevalence. Further, social traditions (e.g., women should bear children and look after their family, which limit women's physical activities) can also play a vital role in increased prevalence of hypertension among women in Bangladesh.

The factors behind the increased prevalence of hypertension in the Bangladeshi adult population could be multifarious [13]. In addition to the common risk factors for hypertension such as a high salt intake, being obese, the excessive use of alcohol, physical inactivity, stress, air pollution and smoking [77], other factors including a regional change in disease patterns from communicable to noncommunicable diseases, rapid urbanization, and obsession for embracing western lifestyle could also influence high hypertension prevalence $[13,14,78$, 79]. Fast-Growing unplanned urbanization as seen in developing countries can potentially lead to change in lifestyles (e.g., change in physical activity, diet, environment, and stress) [13]. In developing countries like Bangladesh, lifestyle, environment, and dietary patterns are quite different in urban and rural areas [14]. These factors are closely linked with a higher prevalence of hypertension and are evident in our study where a higher pooled prevalence of hypertension observed among the urban population (25\% compared to $15 \%$ in the rural population). An extremely high between-study heterogeneity in the prevalence of hypertension was observed. Consequently, we carried out subgroup analysis according to the cut-off level used to define 


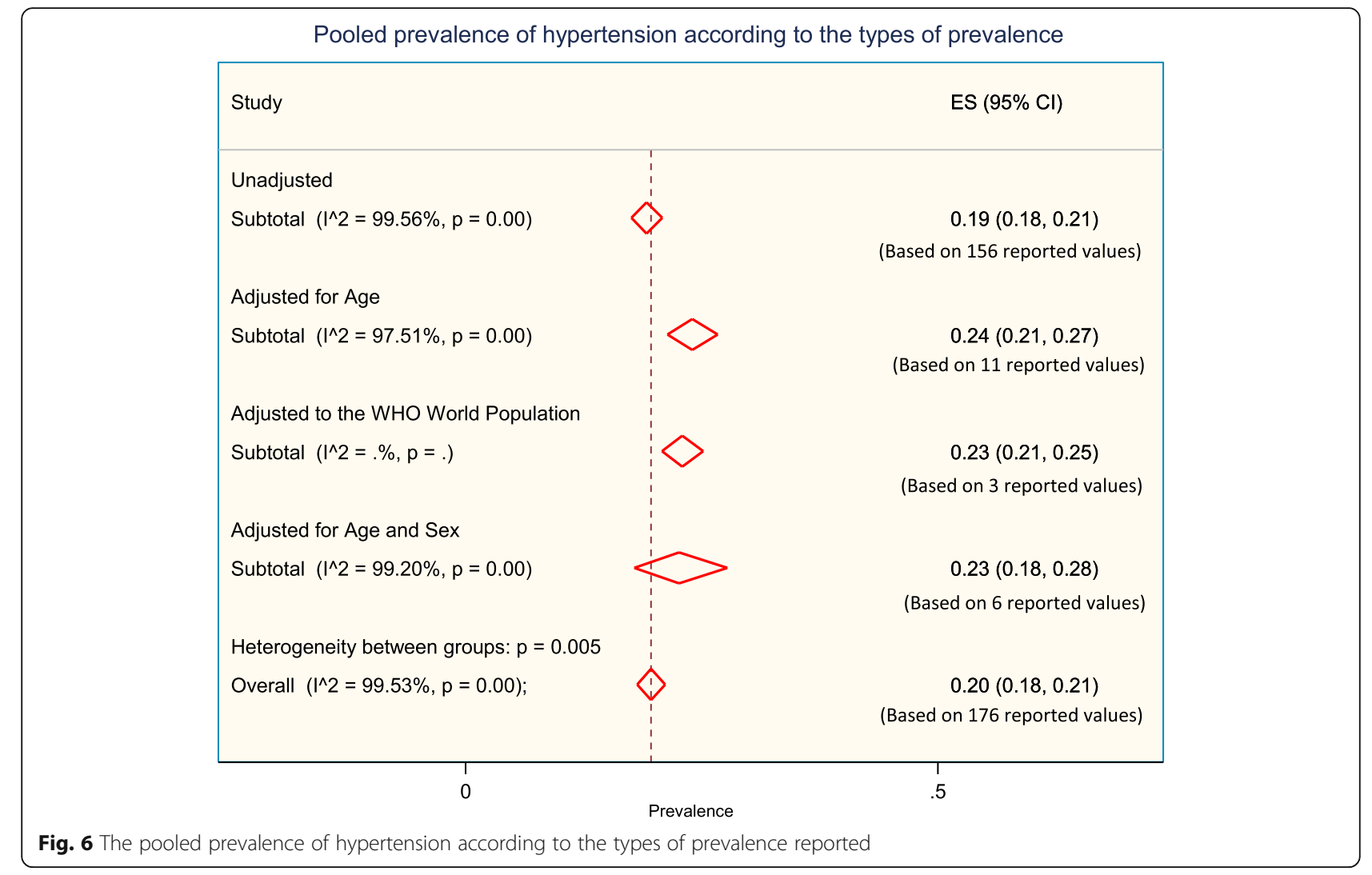

hypertension, types of prevalence, gender, age group and geographical location of the study participants. However, heterogeneity was still observed within all the subgroups and within all the groups of subgroups and we could not explore the possible source of heterogeneity. We observed evidence of small study effect $(p<0.001)$, in which smaller studies reported a higher prevalence of hypertension. Publication bias was also indicated by the asymmetry of the funnel plot.

The strength of this study is the comprehensiveness of the process, which is a search of three different databases, well-defined inclusion/exclusion criteria, and extensive use of reference lists. Consequently, there is little chance that any relevant studies would have been missed. However, there are also several limitations to our study. We could not consider non- English publications and local journals that are not available through major international databases. In addition, a lack of uniform definition of hypertension, and the large variations in the age of the study participants in the included studies can potentially limit the comparability of our findings. As such, pooled prevalence estimates derived from the subgroup analysis can be more accurate and reliable in presenting hypertension prevalence than the overall pooled results. We identified few studies, which potentially considered adolescents with adults as study participants. In those studies, only the lower limit of the study participants' age was provided without any information on the prevalence of hypertension among adolescents. Considering the difference in definition of hypertension for the adults and adolescents, excluding them from the analysis could potentially strengthen our study findings. The differences in the research design of the studies may also influence pooled estimates and can be a potential source of heterogeneity, which we could not explore. Prevalence estimates of hypertension are anticipated to be more precise if studies reported adjusted (for age and gender) estimates. However, most of the studies reported unadjusted prevalence and only a few studies reported age and gender-adjusted hypertension prevalence a point to be noted. Although we identified the existence of high heterogeneity in the studies and attempted subgroup analysis to overcome the issue, heterogeneity still remains and failing to explore potential sources of heterogeneity is another limitation of our study. Performing further subgroup analyses within subgroups or meta-regression according to study setting, sample size, publication year and so on may 

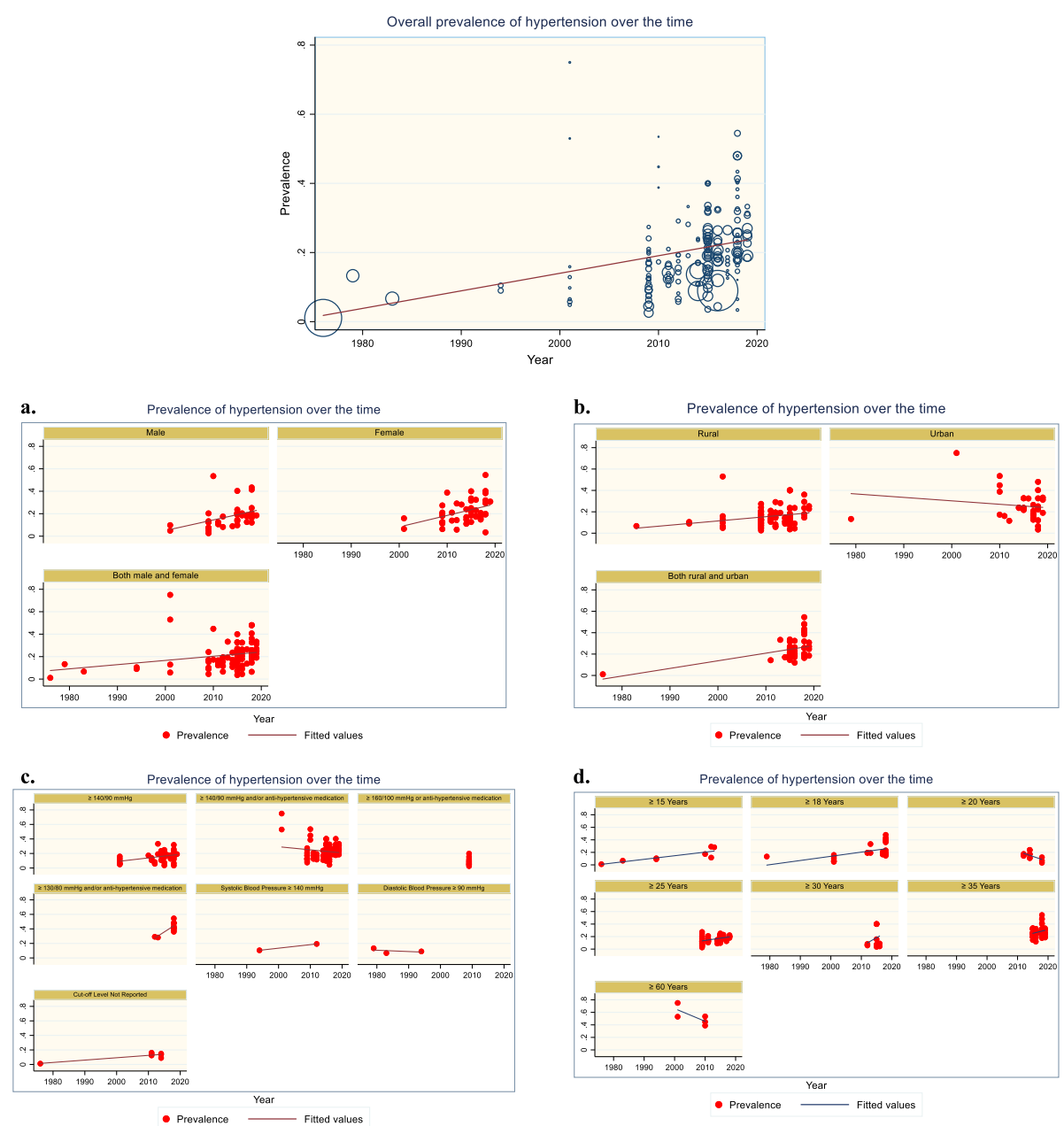

Fig. 7 The overall prevalence of hypertension over time. a. Prevalence of hypertension over time according to the gender of the study participants. b. Prevalence of hypertension over time according to the geographical location of the study participants. c. Prevalence of hypertension over time according to the cut-off level used to define hypertension. $\mathbf{d}$. Prevalence of hypertension over time according to the age group of the study participants

help to explore the sources of heterogeneity. Nevertheless, despite the high heterogeneity of the studies included in our review, the derived pooled estimates are reliable and within the range of prevalence of hypertension described in neighboring countries [72]. In our systematic review, we did not find rigorous population based cross-sectional study with large sample size conducted in the Bangladeshi population for estimating hypertension prevalence. Despite our meta-analysis approach, the lack of comprehensive studies in Bangladeshi population needs to be noted. We also suggest being cautious while interpreting our study findings. Bearing in mind prevalence of hypertension can vary due to the cut-off levels used to define hypertension, age groups, gender and geographical location of the study participants, the interpretation of findings should be made accordingly.

\section{Conclusions}

In this review, we tried to systematically evaluate the scientific literature available on the prevalence of hypertension in Bangladesh and attempted to provide comprehensive summary estimates of hypertension prevalence along with its trend. Although, hypertension prevalence varies according to the criterion used to define hypertension, gender, age group and geographic area of subjects studied, the prevalence of hypertension is still high and rising in Bangladesh according to our review. Similar to WHO's target for a $25 \%$ relative reduction in hypertension prevalence by 2025 [80], programs targeted towards primary prevention needs to be initiated to mitigate a further increase in the prevalence. Modifiable risk factors for hypertension, particularly those related with lifestyles need to be identified and addressed. Increased public awareness and knowledge on high hypertension 


\section{Funnel plot with pseudo 95\% confidence limits}

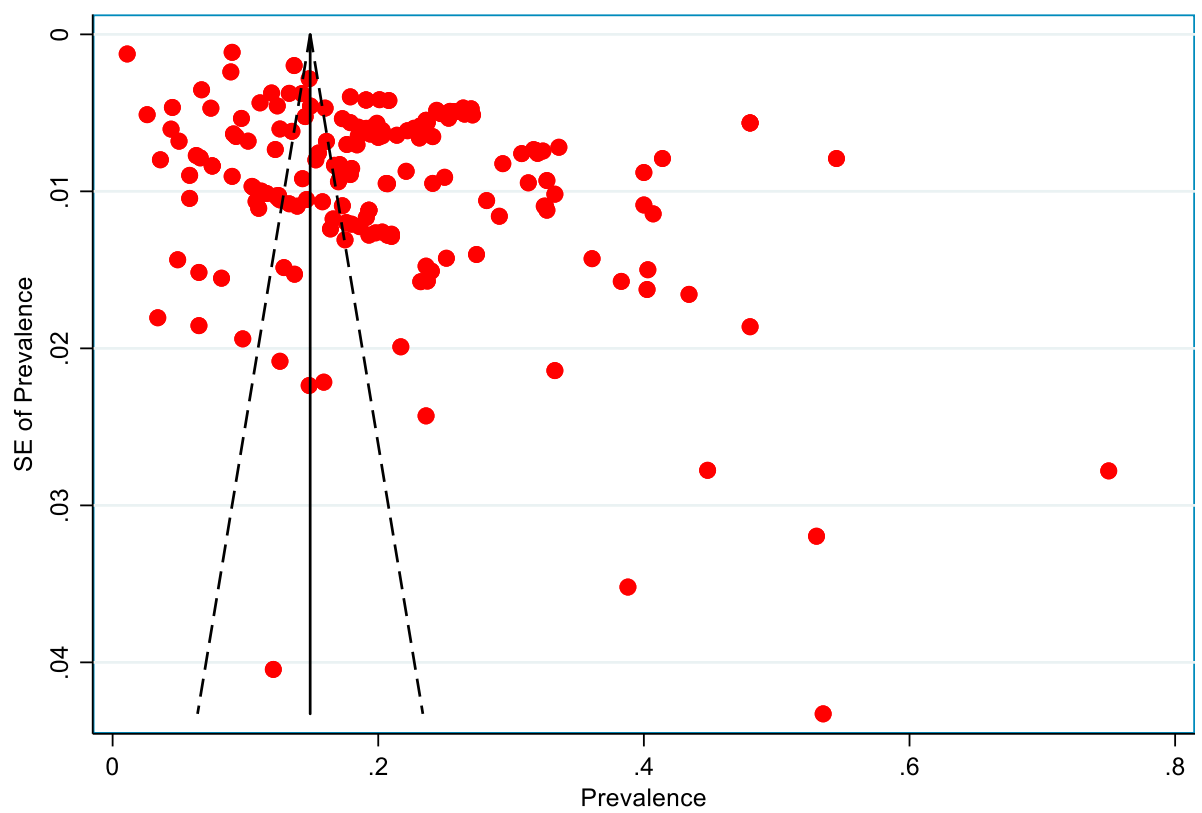

Fig. 8 Funnel plot for the publication bias of the studies that evaluated the prevalence of hypertension in Bangladesh

prevalence, its risk factors, its consequences and its burden along with education programs on diet and healthier lifestyles can be helpful to prevent and confront the issue. Further, well-designed, nationwide, population-based surveillance on hypertension is warranted to provide more up to date, precise and representative estimates of its prevalence.

\section{Acknowledgments}

None

\section{Ethical approval and consent to participate}

Not applicable.

\section{Authors' contributions}

MZIC developed the study design and concept. MZIC, MMR, TA, TAT, AA, ZF, and MAS helped with article searches, review and selection. MZIC performed the analysis and interpreted the results. MZIC drafted the manuscript with critical intellectual inputs from MMR, NC and TCT. MZIC and TCT worked as methodological advisors. All authors revised it critically for important intellectual content, read and approved the final manuscript.

\section{Funding}

This research received no grant from any funding agency in the public, commercial or not-for-profit sectors

\section{Availability of data and materials}

The full list of data and the data entries for all included studies is provided in the paper. No additional supporting data is available.

\section{Consent for publication}

Not applicable.

\section{Competing interests}

The authors declare that they have no competing interests.

\section{Author details}

'Department of Community Health Sciences, University of Calgary, TRW Building (3rd Floor), 3280 Hospital Drive NW, Calgary, Alberta T2N 4Z6,

Canada. ${ }^{2}$ Department of Statistics, Shahjalal University of Science and

Technology, Sylhet, Bangladesh. ${ }^{3}$ Department of Family Medicine, University of Calgary, Calgary, Alberta, Canada.

Received: 9 January 2020 Accepted: 26 March 2020

Published online: 01 June 2020

\section{References}

1. Stanaway JD, Afshin A, Gakidou E, Lim SS, Abate D, Abate KH, et al. Regional, and national comparative risk assessment of 84 behavioural, environmental and occupational, and metabolic risks or clusters of risks for 195 countries and territories, 1990-2017: a systematic analysis for the Global Burden of Disease Study 2017. Lancet. 2018;392:1923-94.

2. Whelton PK, Carey RM, Aronow WS, Casey DE, Collins K, Himmelfarb CD, et al. 2017 ACC/AHA/AAPA/ABC/ACPM/AGS/APhA/ASH/ASPC/NMA/PCNA Guideline for the prevention, detection, evaluation, and management of high blood pressure in adults: a report of the American College of Cardiology/American Heart Association Task Force on Clinical Practice Guidelines. J Am Coll Cardio. 2018;71:e127-248.

3. Rapsomaniki E, Timmis A, George J, Pujades-Rodriguez M, Shah AD, Denaxas $\mathrm{S}$, et al. Blood pressure and incidence of twelve cardiovascular diseases: lifetime risks, healthy life-years lost, and age-specific associations in 1.25 million people. Lancet. 2014;383:1899-911.

4. Vaes B, Beke E, Truyers C, Elli S, Buntinx F, Verbakel JY, et al. The correlation between blood pressure and kidney function decline in older people: a registry-based cohort study. BMJ Open. 2015;5:e007571.

5. Tzourio C. Hypertension, cognitive decline, and dementia: an epidemiological perspective. Dialog Clin Neur. 2007;9:61.

6. Bloch MJ, FASH F, Basile FJ. Cardiovascular risks of hypertension. UpToDate. Jan. 2018.

7. Mendis S, Puska P, Norrving B, World Health Organization. Global atlas on cardiovascular disease prevention and control. Geneva: WHO; 2011.

8. Sarki AM, Nduka CU, Stranges S, Kandala NB, Uthman OA. Prevalence of hypertension in low-and middle-income countries: a systematic review and meta-analysis. Medicine. 2015:94. 
9. Kearney PM, Whelton M, Reynolds K, Muntner P, Whelton PK, He J. Global burden of hypertension: analysis of worldwide data. Lancet. 2005:365:21723.

10. Mills KT, Bundy JD, Kelly TN, Reed JE, Kearney PM, Reynolds K, et al. Global disparities of hypertension prevalence and control: a systematic analysis of population-based studies from 90 countries. Circulation. 2016;134:441-50.

11. World Health Organization. A global brief on hypertension: silent killer, global public health crisis: World Health Day 2013. WHO; 2013.

12. Islam M P1-181 Mortality and epidemiological transition in Bangladesh: lessons and experiences to the developing countries in the new millennium. J Epid Com Health. 2011 Aug 1; 65(Suppl 1): A116-

13. Chowdhury MZ, Anik AM, Farhana Z, Bristi PD, Al Mamun BA, Uddin MJ, et al. Prevalence of metabolic syndrome in Bangladesh: a systematic review and meta-analysis of the studies. BMC Public Health. 2018;18:308.

14. Chowdhury MZ, Haque MA, Farhana Z, Anik AM, Chowdhury AH, Haque SM, et al. Prevalence of cardiovascular disease among Bangladeshi adult population: a systematic review and meta-analysis of the studies. Vascu Health Risk Msanag. 2018;14:165.

15. Riley RD, Higgins JP, Deeks JJ. Interpretation of random effects metaanalyses. BMJ. 2011;342:d549.

16. Higgins JP, Thompson SG, Deeks JJ, Altman DG. Measuring inconsistency in meta-analyses. BMJ. 2003;327:557.

17. Higgins J, Thompson SG. Quantifying heterogeneity in a meta-analysis. Stat Med. 2002;21:1539-58

18. Zaman MM, Yoshiike N, Rouf MA, Syeed MH, Khan MR, Haque S, et al. Cardiovascular risk factors: distribution and prevalence in a rural population of Bangladesh. J Cardiovasc Risk. 2001;8(2):103-8.

19. Zaman M, Rahman MM, Rahman MR, Bhuiyan M, Karim MN, Chowdhury MA. Prevalence of risk factors for non-communicable diseases in Bangladesh: results from STEPS survey 2010. Ind J Pub Health. 2016;60:17-25.

20. Zaman MM, Bhuiyan MR, Karim MN, Rahman MM, Akanda AW, Fernando T. Clustering of non-communicable diseases risk factors in Bangladeshi adults: an analysis of STEPS survey 2013. BMC Public Health. 2015;15:659.

21. Van Minh H, Soonthornthada K, Ng N, Juvekar S, Razzaque A, Ashraf A, et al Blood pressure in adult rural INDEPTH population in Asia. Global Health Action. 2009;2(1):2010.

22. Tareque MI, Koshio A, Tiedt AD, Hasegawa T. Are the rates of hypertension and diabetes higher in people from lower socioeconomic status in Bangladesh? Results from a nationally representative survey. PloS One. 2015; 10(5):e0127954.

23. Sayeed MA, Mahtab H, Latif ZA, Khanam PA, Ahsan KA, Banu A, et al Waistto-height ratio is a better obesity index than body mass index and waist-tohip ratio for predicting diabetes, hypertension, and lipidemia. Bangl Med Res Coun Bul 2003; 29:1-0.

24. Sayeed MA, Banu A, Haq JA, Khanam PA, Mahtab H, Azad AK. Prevalence of hypertension in Bangladesh: effect of socioeconomic risk factor on difference between rural and urban community. Bangl Med Res Coun Bul. 2002;28:7-18.

25. Razzaque A, Nahar L, Mustafa AH, Ahsan KZ, Islam MS, Yunus M Sociodemographic differentials of selected noncommunicable diseases risk factors among adults in Matlab, Bangladesh: findings from a WHO STEPS survey. Asi Pac J Pub Health. 2011;23:183-91.

26. Rahman MM, Gilmour S, Akter S, Abe SK, Saito E, Shibuya K. Prevalence and control of hypertension in Bangladesh: a multilevel analysis of a nationwide population-based survey. J Hypertens. 2015:33:465-72.

27. Hypertension Study Group. Prevalence, awareness, treatment, and control of hypertension among the elderly in Bangladesh and India: a multicentre study. Bul WHO. 2001; 79:490.

28. Parr JD, Lindeboom W, Khanam MA, Koehlmoos TL. Diagnosis of chronic conditions with modifiable lifestyle risk factors in selected urban and rural areas of Bangladesh and sociodemographic variability therein. BMC Health Ser Res. 2011;11:309.

29. Alam DS, Chowdhury MA, Siddiquee AT, Ahmed S, Niessen LW. Awareness and control of hypertension in Bangladesh: follow-up of a hypertensive cohort. BMJ Open. 2014;4:e004983.

30. Huda MN, Alam KS. Prevalence of chronic kidney disease and its association with risk factors in disadvantageous population. Int J Neph. 2012;2012

31. Khanam MA, Lindeboom W, Razzaque A, Niessen L, Milton AH. Prevalence and determinants of pre-hypertension and hypertension among the adults in rural Bangladesh: findings from a community-based study. BMC Public Health. 2015;15:203.
32. Khanam MA, Lindeboom W, Razzaque A, Niessen L, Smith W, Milton AH. Undiagnosed and uncontrolled hypertension among the adults in rural Bangladesh: findings from a community-based study. J Hypertens. 2015;33: 2399-406.

33. Khanam MA, Lindeboom W, Koehlmoos TL, Alam DS, Niessen L, Milton AH. Hypertension: adherence to treatment in rural Bangladesh-findings from a population-based study. Global Health Action. 2014;7(1):25028.

34. Jesmin S, Islam AS, Akter S, Islam MM, Sultana SN, Yamaguchi N, et al. Metabolic syndrome among pre-and post-menopausal rural women in Bangladesh: result from a population-based study. BMC Res Not. 2013;6(1): 157.

35. Jesmin S, Islam MR, Islam AS, Mia MS, Sultana SN, Zaedi S, Yamaguchi N, Iwashima Y, Hiroe M, Watanabe T. Comprehensive assessment of metabolic syndrome among rural Bangladeshi women. BMC Public Health. 2012;12(1): 49.

36. Islam SM, Mainuddin AK, Islam MS, Karim MA, Mou SZ, Arefin S, Chowdhury KN. Prevalence of risk factors for hypertension: A cross-sectional study in an urban area of Bangladesh. Glo Cardio Sci Prac. 2015;20:43.

37. Islam M, Khan I, Attia J, Hassan S, McEvoy M, D'Este C, et al. Association between hypertension and chronic arsenic exposure in drinking water: A cross-sectional study in Bangladesh. Int J Environ Res Pub Health. 2012;9:4522-36.

38. Islam GR. The risk of developing cardiovascular disease in Bangladesh: does diabetes mellitus matter? Which socioeconomic status does it impact? A cross-sectional study. J Am Soc Hypertens. 2017;11:45-53.

39. Islam FM, Bhuiyan A, Chakrabarti R, Rahman MA, Kanagasingam Y, Hiller JE. Undiagnosed hypertension in a rural district in Bangladesh: The Bangladesh Population-based Diabetes and Eye Study (BPDES). J Hum Hypertens. 2016;30:252.

40. Hasan MJ, Muqueet A, Sharmeen A, Rahman M, Ahmed TU, Haque A, et al. Prevalence of Diabetes mellitus, Hypertension, and Proteinuria in a Rural area of Bangladesh. Commu-Based Med J. 2012;1:8-13.

41. Karim AN, Das D, Salahuddin M, Marjan GA, Islam MN, Shaha AK, et al. Prevalence of microalbuminuria and overt proteinuria in hypertension and their relations with renal function in a rural population of Bangladesh. Bangl Med. 2013;24:59-64

42. Harshfield E, Chowdhury R, Harhay MN, Bergquist H, Harhay MO. Association of hypertension and hyperglycaemia with socioeconomic contexts in resource-poor settings: the Bangladesh Demographic and Health Survey. Int J Epid. 2015:44:1625-36.

43. Fatema K, Zwar NA, Milton AH, Rahman B, Awal AS, Ali L. Cardiovascular risk assessment among rural population: findings from a cohort study in a peripheral region of Bangladesh. Public Health. 2016;137:73-80.

44. Fatema K, Zwar NA, Zeba Z, Milton AH, Rahman B, Ali L. Clinical and biochemical characterization of high risk and not high risk for cardiovascular disease adults in a population from peripheral region of Bangladesh. BMC Public Health. 2015:15:559.

45. Chowdhury MA, Uddin MJ, Haque MR, Ibrahimou B. Hypertension among adults in Bangladesh: evidence from a national cross-sectional survey. BMC Cardio Disord. 2016;16:22.

46. Hasan MJ, Kashem MA, Rahman MH, Quddhush R, Rahman M, Sharmeen A, Islam N. Prevalence of chronic kidney disease (CKD) and identification of associated risk factors among rural population by mass screening. CommuBased Med J. 2012;1(1):20-6.

47. Chakrabarti R, Finger RP, Lamoureux E, Islam MT, Dirani M, Bhuiyan A, Islam SZ, Wahab MA, Islam FM. Rationale and methodology for a populationbased study of diabetes and common eye diseases in a rural area in Bangladesh: Bangladesh Population based Diabetes and Eye Study (BPDES). Bangl J Med Sci. 2015;14:367-75.

48. Bishwajit G, Yaya S, Seydou I. Diabetes mellitus and high blood pressure in relation to BMI among adult non-pregnant women in Bangladesh. Diabetes Metab Syndrome. 2017;11:S217-21.

49. Bhowmik B, Binte Munir S, Ara Hossain I, Siddiquee T, Diep LM, Mahmood S, Mahtab H, Khan AK, Hussain A. Prevalence of type 2 diabetes and impaired glucose regulation with associated cardiometabolic risk factors and depression in an urbanizing rural community in Bangladesh: a populationbased cross-sectional study. Diab Metab J. 2012;36:422-32.

50. Alam DS, Chowdhury MA, Siddiquee AT, Ahmed S, Niessen LW. Awareness and control of hypertension in Bangladesh: follow-up of a hypertensive cohort. BMJ Open. 2014:4(12):e004983.

51. Moni MA, Rahman MA, Haque MA, Islam MS, Ahmed K. Blood pressure in relation to selected anthropometric measurements in senior citizens. MMJ. 2010;19:254-8. 
52. Das S, Dutta PK. Chronic kidney disease prevalence among health care providers in Bangladesh. MMJ. 2010;19:415-21.

53. Sayeed MA, Khan AR, Banu A, Hussain MZ, Ali SM. Blood pressure and glycemic status in relation to body mass index in a rural population of Bangladesh. Bangl Med Res Coun Bul. 1994;20:27-35.

54. Islam N, Khan M, Latif ZA. Hypertension in the rural population of Bangladesh--a preliminary survey. Bangl Med Res Coun Bul. 1983;9:11-4.

55. Islam N, Janan FA, Chowdhury NA, Ahmed Z, Mathura KC. Hypertension in Secretariate population of Bangladesh. Bangl Med Res Coun Bul. 1979;5:1924

56. Malik A. Congenital and acquired heart diseases :( A survey of 7062 persons). Bangl Med Res Coun Bul. 1976;2:115-9.

57. Mondal RN, Haque MA, Jahan SM, Azad AK, Rahman MM, Rani M, et al. Prevalence and risk factors of hypertension in Rangpur, Bangladesh. World Heart J. 2013:5:91.

58. Sayeed MA, Banu A, Khan AR, Hussain MZ. Prevalence of diabetes and hypertension in a rural population of Bangladesh. Diabetes Care. 1995;18: $555-8$.

59. Khalequzzaman M, Chiang C, Choudhury SR, Yatsuya H, Al-Mamun MA, AlShoaibi AA, et al. Prevalence of non-communicable disease risk factors among poor shantytown residents in Dhaka, Bangladesh: a communitybased cross-sectional survey. BMJ Open. 2017;7(11):e014710.

60. Ali N, Mahmood S, Manirujijaman M, Perveen R, Al Nahid A, Ahmed S, et al. Hypertension prevalence and influence of basal metabolic rate on blood pressure among adult students in Bangladesh. BMC Public Health. 2018; 18(1):58.

61. Biswas T, Townsend N, Islam MS, Islam MR, Gupta RD, Das SK, et al. Association between socioeconomic status and prevalence of noncommunicable diseases risk factors and comorbidities in Bangladesh: findings from a nationwide cross-sectional survey. BMJ Open. 2019;9(3): e025538.

62. Al Kibria GM, Swasey K, Choudhury A, Burrowes V, Stafford KA, Uddin SI, et al. The new 2017 ACC/AHA guideline for classification of hypertension: changes in prevalence of hypertension among adults in Bangladesh. J Hum Hypertens. 2018;32:608.

63. Islam JY, Zaman MM, Haq SA, Ahmed S, Al-Quadir Z. Epidemiology of hypertension among Bangladeshi adults using the 2017 ACC/AHA Hypertension Clinical Practice Guidelines and Joint National Committee 7 Guidelines. J Hum Hypertens. 2018:32:668.

64. Rawal LB, Biswas T, Khandker NN, Saha SR, Chowdhury MM, Khan AN, Chowdhury EH, Renzaho A. Non-communicable disease (NCD) risk factors and diabetes among adults living in slum areas of Dhaka, Bangladesh. PloS One. 2017;12(10):e0184967.

65. Roy PK, Khan MH, Akter T, Rahman MS. Exploring socio-demographic-and geographical-variations in prevalence of diabetes and hypertension in Bangladesh: Bayesian spatial analysis of national health survey data. Spatial Spatio Temporal Epid. 2019;29:71-83.

66. Ahmed S, Tariqujjaman M, Rahman MA, Hasan MZ, Hasan MM. Inequalities in the prevalence of undiagnosed hypertension among Bangladeshi adults: evidence from a nationwide survey. Int J Equi Health. 2019;18:33.

67. Al Kibria GM, Swasey K, Gupta RD, Choudhury A, Nayeem J, Sharmeen A Burrowes V. Differences in prevalence and determinants of hypertension according to rural-urban place of residence among adults in Bangladesh. Bio Sci. 2018;19:1-3.

68. Al Kibria GM, Swasey K, Hasan MZ, Choudhury A, Gupta RD, Abariga SA Sharmeen $A$, Burrowes $V$. Determinants of hypertension among adults in Bangladesh as per the Joint National Committee 7 and 2017 American College of Cardiology/American Hypertension Association hypertension guidelines. J Am Soc Hypertens. 2018;12:e45-55.

69. Rahman M, Zaman MM, Islam JY, Chowdhury J, Ahsan HN, Rahman R, et al. Prevalence, treatment patterns, and risk factors of hypertension and prehypertension among Bangladeshi adults. J Hum Hypertens. 2018;32(5):334.

70. Biswas RK, Kabir E. Influence of distance between residence and health facilities on non-communicable diseases: An assessment over hypertension and diabetes in Bangladesh. PloS One. 2017;12(5):e0177027.

71. NCD Risk Factor Collaboration. Worldwide trends in blood pressure from 1975 to 2015: a pooled analysis of 1479 population-based measurement studies with 19. 1 million participants. Lancet (London, England). 2017 Jan 7; 389 (10064):37.

72. World Health Organization. Noncommunicable diseases country profiles 2014.
73. Ahmad A, Oparil S. Hypertension in women: recent advances and lingering questions. Hypertension. 2017;70(1):19-26.

74. Choi HM, Kim HC, Kang DR. Sex differences in hypertension prevalence and control: analysis of the 2010-2014 Korea National Health and Nutrition Examination Survey. PloS One. 2017; 12(5).

75. Peltzer $\mathrm{K}$, Pengpid $\mathrm{S}$. The prevalence and social determinants of hypertension among adults in Indonesia: A cross-sectional populationbased national survey. Int J Hypertens. 2018;2018.

76. Tailakh A, Evangelista LS, Mentes JC, Pike NA, Phillips LR, Morisky DE. Hypertension prevalence, awareness, and control in Arab countries: A systematic review. Nurs Health Sci. 2014;16(1):126-30.

77. A global brief on hypertension. Geneva: World Health Organization; 2013. (http://www.who.int/cardiovascular_diseases/publications/global_brief_ hypertension/en/, accessed 17 August 2019).

78. Low WY, Lee YK, Samy AL. Non-communicable diseases in the Asia-Pacific region: prevalence, risk factors, and community-based prevention. Int J Occup Med Environ Health. 2015;28:20-6.

79. Misra A, Khurana L. The metabolic syndrome in South Asians: epidemiology, determinants, and prevention. Metab Syndr Relat Disord. 2009;7:497-514.

80. Global action plan for the prevention and control of noncommunicable diseases 2013-2020. Geneva: WHO; 2013. (http://www.who.int/nmh/events/ ncd_action_plan/en/, accessed 16 August 2019).

\section{Publisher's Note}

Springer Nature remains neutral with regard to jurisdictional claims in published maps and institutional affiliations.
Ready to submit your research? Choose BMC and benefit from:

- fast, convenient online submission

- thorough peer review by experienced researchers in your field

- rapid publication on acceptance

- support for research data, including large and complex data types

- gold Open Access which fosters wider collaboration and increased citations

- maximum visibility for your research: over $100 \mathrm{M}$ website views per year

At BMC, research is always in progress.

Learn more biomedcentral.com/submissions 